\title{
Systemic administration of urocortin after intracerebral hemorrhage reduces neurological deficits and neuroinflammation in rats
}

\author{
Hock-Kean Liew ${ }^{1,2}$, Cheng-Yoong Pang ${ }^{2,3}$, Chih-Wei Hsu ${ }^{4,5}$, Mei-Jen Wang ${ }^{2,3}$, Ting-Yi Li ${ }^{2}$, Hsiao-Fen Peng ${ }^{2}$,
} Jon-Son $\mathrm{KuO}^{3}$ and Jia-Yi Wang ${ }^{1,6^{*}}$

\begin{abstract}
Background: Intracerebral hemorrhage $(\mathrm{ICH})$ remains a serious clinical problem lacking effective treatment. Urocortin (UCN), a novel anti-inflammatory neuropeptide, protects injured cardiomyocytes and dopaminergic neurons. Our preliminary studies indicate UCN alleviates ICH-induced brain injury when administered intracerebroventricularly (ICV). The present study examines the therapeutic effect of UCN on ICH-induced neurological deficits and neuroinflammation when administered by the more convenient intraperitoneal (i.p.) route.

Methods: ICH was induced in male Sprague-Dawley rats by intrastriatal infusion of bacterial collagenase VII-S or autologous blood. UCN (2.5 or $25 \mu \mathrm{g} / \mathrm{kg}$ ) was administered i.p. at 60 minutes post-ICH. Penetration of i.p. administered fluorescently labeled UCN into the striatum was examined by fluorescence microscopy. Neurological deficits were evaluated by modified neurological severity score (mNSS). Brain edema was assessed using the dry/ wet method. Blood-brain barrier (BBB) disruption was assessed using the Evans blue assay. Hemorrhagic volume and lesion volume were assessed by Drabkin's method and morphometric assay, respectively. Pro-inflammatory cytokine (TNF- $\alpha, I L-1 \beta$, and IL-6) expression was evaluated by enzyme-linked immunosorbent assay (ELISA). Microglial activation and neuronal loss were evaluated by immunohistochemistry.
\end{abstract}

Results: Administration of UCN reduced neurological deficits from 1 to 7 days post-ICH. Surprisingly, although a higher dose $(25 \mu \mathrm{g} / \mathrm{kg}$, i.p.) also reduced the functional deficits associated with $\mathrm{ICH}$, it is significantly less effective than the lower dose $(2.5 \mu \mathrm{g} / \mathrm{kg}$, i.p.). Beneficial results with the low dose of UCN included a reduction in neurological deficits from 1 to 7 days post- $\mathrm{ICH}$, as well as a reduction in brain edema, BBB disruption, lesion volume, microglial activation and neuronal loss 3 days post-ICH, and suppression of TNF- $\alpha$, IL-1 $\beta$, and IL-6 production 1, 3 and 7 days post-ICH.

Conclusion: Systemic post-ICH treatment with UCN reduces striatal injury and neurological deficits, likely via suppression of microglial activation and inflammatory cytokine production. The low dose of UCN necessary and the clinically amenable peripheral route make UCN a potential candidate for development into a clinical treatment regimen.

Keywords: anti-neuroinflammation, brain edema, intracerebral hemorrhage, urocortin

\section{Background}

Spontaneous intracerebral hemorrhage $(\mathrm{ICH})$ accounts for approximately $15 \%$ of stroke incidents in Western populations and an even higher proportion, up to 20$30 \%$, in Asian populations [1]. ICH is one of the most

\footnotetext{
* Correspondence: jywang2010@tmu.edu.tw

'Graduate Institute of Life Sciences, National Defense Medical Center, Taipei, Taiwan

Full list of author information is available at the end of the article
}

lethal and destructive types of stroke and mortality is high, at 30\%-50\% [2]. Despite a number of promising trials, no medical or surgical therapy has shown any benefit for ICH patients [3]. No drug increases survival in ICH patients [4]. Early surgical removal of the blood clot shows no overall benefit over more conservative therapy [5-7]. Therefore, the prognosis for ICH patients is poor.

\section{Biomed Central}

(c) 2012 Liew et al; licensee BioMed Central Ltd. This is an Open Access article distributed under the terms of the Creative Commons Attribution License (http://creativecommons.org/licenses/by/2.0), which permits unrestricted use, distribution, and reproduction in any medium, provided the original work is properly cited. 
Pathological changes in $\mathrm{ICH}$ can be divided into primary and secondary brain injury. Primary injury occurs rapidly as a result of physical destruction of tissues and mass expansion of the hematoma [1], and is difficult to be the therapeutic target. Secondary injury commonly occurs when the tissue reacts to blood breakdown components in the parenchyma adjacent to the hematoma, initiating a series of inflammatory responses including the activation of inflammatory cells, brain edema, bloodbrain barrier (BBB) disruption and apoptosis [8]. Secondary injury often develops hours to days after the ICH insult [8], making it a practical therapeutic target. Therefore, there is still hope for using anti-inflammatory agents in $\mathrm{ICH}$ therapy. Urocortin (UCN) may be an ideal candidate.

UCN, a 40-amino-acid endogenous neuropeptide, belongs to the corticotrophin releasing hormone (CRH) family of peptides, which bind two G-protein coupled receptors, CRH-R1 and CRH-R2 $[9,10]$. These receptors are expressed in brain neurons and glial cells [11-14] in many brain regions [15], involved in the regulation of anxiety, learning and memory, body temperature, stress responses [15] and hypotension $[9,16]$. More importantly, UCN is considered a powerful anti-inflammatory agent by the following reports.

Intravenously administered UCN is effective in the treatment of heart ischemia/reperfusion injury [17-20]. UCN locally administered in the substantia nigra alleviates lipopolysaccharide (LPS)-induced cytotoxicity of dopaminergic neurons [21]. In our previous in vitro studies, we showed that UCN alleviates inflammation and neurotoxicity mediated by endotoxin-activated microglia $[22,23]$; while in our in vivo study, intracerebroventricular (ICV) treatment with UCN post-ICH reduces brain injury area, brain edema, and BBB permeability. These reductions are associated with improved neurological deficits [24]. Considering the safety and convenience of systemic administration for clinical application, we further examined the effectiveness of systemic administration of UCN in rats with experimentally induced $\mathrm{ICH}$ and elucidated the anti-neuroinflammatory effects of this treatment.

\section{Materials and methods Experimental design}

All experimental protocols were approved by the Animal Care and Use Committee of the Tzu Chi University and National Defense Medical Center, Taiwan in accordance with guidelines set by the National Institutes of Health Guide for the Care and Use of Laboratory Animals. Animals were housed under a 12 hour light/dark cycle with free access to food and water. Utmost efforts were made to minimize the suffering and the number of animals used.
In total, 165 rats were randomly divided into the following six groups:

1. Sham + saline group $(n=17)$. Rats were infused with $1 \mu$ saline into the striatum over 10 minutes, to mimic the collagenase infusion described below. At 60 minutes post-sham-ICH induction, a total of $0.2 \mathrm{ml}$ of sterile saline was administered i.p. to control for UCN treatment.

2 . $\mathrm{ICH}+$ saline group, collagenase model $(\mathrm{n}=59)$. Sterile saline $(0.2 \mathrm{ml})$ was administered i.p. to each animal at 60 minutes post-ICH induction by intrastriatal infusion of collagenase VII-S.

3. $\mathrm{ICH}+\mathrm{L}-\mathrm{UCN}$ group, collagenase model $(\mathrm{n}=53)$. A low dose $(2.5 \mu \mathrm{g} / \mathrm{kg}$ in $0.2 \mathrm{ml}$ sterile saline, intraperitoneally) of UCN was administered to each animal at 60 minutes post-ICH.

4. $\mathrm{ICH}+\mathrm{H}-\mathrm{UCN}$ group, collagenase model $(\mathrm{n}=24)$. A high dose $(25 \mu \mathrm{g} / \mathrm{kg}$ in $0.2 \mathrm{ml}$ sterile saline, i.p.) of $\mathrm{UCN}$ was administered to each animal at 60 minutes post-ICH.

The UCN doses were chosen according to previous studies [9,16,25-29].

5. ICH + saline group, blood infusion model $(n=6)$. $0.2 \mathrm{ml}$ sterile saline was administered i.p. to each animal at 60 minutes post- $\mathrm{ICH}$ induction by intrastriatal infusion of $100 \mu \mathrm{l}$ of autologous blood.

6. ICH + L-UCN group, blood infusion model $(n=6)$. A low dose $(2.5 \mu \mathrm{g} / \mathrm{kg}$ in $0.2 \mathrm{ml}$ sterile saline, i.p.) of UCN was administered to each animal at 60 minutes post-ICH

\section{ICH models}

Male Sprague-Dawley rats (250-300 g) anesthetized with chloral hydrate $(0.4 \mathrm{~g} / \mathrm{kg}$, i.p., Sigma-Aldrich, St. Louis, MO, USA). ICH was induced by stereotaxic infusion of bacterial collagenase VII-S $(0.23 \mathrm{U}$ in $1.0 \mu \mathrm{l}$ sterile saline, Sigma-Aldrich) over a period of 10 minutes, or infusion of $100 \mu \mathrm{l}$ autologous blood from the tail vein over 60 seconds, into the striatum $(0.0 \mathrm{~mm}$ posterior, 3.0 $\mathrm{mm}$ right, $5.0 \mathrm{~mm}$ ventral to bregma at the skull surface) $[30,31]$. The needle was kept in place for another 10 minutes to prevent backflow. The craniotomies were sealed with bone wax. Rats were allowed to recover in separate cages at room temperature.

\section{Evaluation of physiological parameters}

Another 22 rats were randomly assigned for evaluation of physiological parameters including mean arterial blood pressure, blood gases, body weight changes and body temperature. Under urethane $(1.0 \mathrm{~g} / \mathrm{kg}$ bodyweight, i.p., Sigma-Aldrich) anesthesia, a femoral artery was cannulated with a PE-50 polyethylene tube for supplementation of fluid and monitoring of arterial blood pressure and blood gas. Arterial blood pressure was recorded 
through an amplifier (MP35, BIOPAC system, CA, USA) and stored in a $\mathrm{PC}$ computer. Body temperature (rectal temperature) was automatically maintained at $37.5 \pm$ $0.5^{\circ} \mathrm{C}$ by a rectal temperature sensor and a heating pad (CMA-150, Sweden). The physiological parameters were measured 10 minutes before (baseline), and 0.5, 1 and 3 hours after treatment with UCN or saline.

\section{Evaluation of regional Cerebral Blood Flow (rCBF)}

Another 12 rats were randomly assigned for evaluation of $\mathrm{rCBF}$. The $\mathrm{rCBF}$ was monitored with a laser probe (MNP 110XP, Oxford Optronix, UK) inserted during surgery and connected to a Laser Doppler Blood Flow Perfusion Monitor 403A (OxyFlo 2000, Oxford Optronix, UK). The probe was placed in the peri-hematomal region in the striatum $(0.0 \mathrm{~mm}$ posterior, $5.0 \mathrm{~mm}$ right, $5.0 \mathrm{~mm}$ ventral to bregma skull surface). We collected the baseline $\mathrm{rCBF}$ data before and the rCBF at 0.5, 1 and 3 hours after collagenase administration. The $\mathrm{rCBF}$ at each time point was collected for 10 minutes and averaged. All data were normalized by the following formula: percentage change $=[(d f) / d F] \times 100$, where $d f$ is the mean flow after administration and $d F$ is the mean flow at baseline.

\section{Assessment of neurological abnormalities}

A total of 36 rats were used in the assessment of the neurological abnormalities by a modified Neurological Severity Score (mNSS) method [32]. The evaluation was performed by an investigator blinded to the experimental treatment scheme. The mNSS is a composite test of motor, sensory, and balance functions. The assessment was performed on day 1 before and on days 1,3 and 7 after ICH. Neurological function was graded on a scale of 0-18 (normal score, 0; maximal deficit score, 18).

\section{Assessment of brain edema}

Brain edema formation peaks at days 3 post-ICH [33,34]. We thus chose this time point to study brain edema, as indicated by tissue water content. A total of 35 rats were randomly used in the assessment of brain water content, using a common wet/dry method as previously described [35]. Briefly, on days 1 and 3 post- $\mathrm{ICH}$, rats were anesthetized and decapitated. The brains were removed and separated into contralateral and ipsilateral hemispheres and cerebellum. The cerebellum was used as an internal control. The sample was weighed to obtain the wet weight immediately, and then dried in an oven at $100^{\circ} \mathrm{C}$ for 24 hours to obtain the dry weight. The water content was expressed as a percentage of the wet weight: [(wet weight)-(dry weight)] (wet weight) ${ }^{-1} \times 100 \%$.

\section{Evaluation of brain penetration of labeled UCN}

Urocortin was labeled with Alexa Fluor ${ }^{\circledR} 488$ dye using a Microscale Protein Labeling Kit (A30006, Invitrogen,
USA), according to the manufacturer's instructions. The Alexa Fluor ${ }^{\circledR} 488$ dye-labeled UCN $(2.5 \mu \mathrm{g})$, with fluorescence excitation and emission maxima of approximately 494 and $519 \mathrm{~nm}$, was administered i.p. one hour after $\mathrm{ICH}$. Three hours after injection of the fluorescently labeled UCN, the rats were re-anesthetized with chloral hydrate $(0.4 \mathrm{~g} / \mathrm{kg}$ i.p. $)$, and their brains were removed immediately and sectioned to 20 $\mu \mathrm{m}$ thickness with a cryostat. To confirm the entrance of urocortin peptide into the brain, $20 \mu \mathrm{m}$ thick brain slices were labeled with anti-UCN antibody. Sections were incubated overnight at $4^{\circ} \mathrm{C}$ with UCN primary antibody (1:100; Catalog No. U4757, Sigma, CA, USA). The slices were then washed with PBS and incubated for 1 hour with secondary antibody (anti-rabbit-Rhodamine, Jackson ImmunoResearch, West Grove, PA, USA) at room temperature. After rinsing with PBS buffer, the slices were examined under a fluorescence microscope. After counter-staining the nuclei with DAPI, the slides were washed and mounted on cover slips with anti-fading mounting medium (VECTASHIELD $^{\circledR}$, CA, USA). The presence of the labeled $\mathrm{UCN}$ in the striatum was evaluated under a fluorescence microscope.

\section{Assessment of hemorrhagic volume and lesion volume}

Hemoglobin content determined by spectrophotometric measurement is a good indication of the hemorrhagic volume (bleeding) on day 1 post-ICH. This volume, however, can be affected by breakdown of the hemoglobin, swelling (edema) of tissue, and production of many inflammatory mediators immediately following the bleeding. Therefore, we conducted both a spectrophotometric measurement for hemorrhagic volume and a morphometric measurement for lesion volume in the $\mathrm{ICH}+$ saline and $\mathrm{ICH}+\mathrm{L}-\mathrm{UCN}$ groups on days 1 and 3 post-ICH.

\section{Assessment of hemorrhagic volume}

Rats were randomly used in the assessment of hemorrhagic volume on day 1 ( $\mathrm{n}=6$, each group) post- $\mathrm{ICH}$. The accumulated hemorrhagic volume was quantified by a spectrophotometric assay as reported by Park et al., with minor modifications [36]. Briefly, both contralateral and ipsilateral hemispheres were removed after transcardial perfusion. PBS was added to the individual hemispheres to make-up a total of $3 \mathrm{ml}$ volume for homogenization and centrifugation (15000 g, $30 \mathrm{~min}-$ utes). The supernatant $(40 \mu \mathrm{l})$ was reacted with Drabkin's reagent (160 $\mu \mathrm{l}$, Sigma) for 15 minutes at room temperature. Optical density was measured at $540 \mathrm{~nm}$ with a spectrophotometer (Molecular Devices OptiMax, USA). Equivalent hemorrhage volume $(\mu \mathrm{l})$ of the supernatant was calculated from a standard curve obtained with known amounts of blood. 


\section{Morphometric measurement of lesion volume}

Rat brain sections were captured for morphometric measurement (image analysis) prior to being used for the cytokine ELISA assay or the dry/wet method (brain edema assay). Briefly, rat brains on day $1(n=6$, each group) and day $3(\mathrm{n}=12$, each group) post-ICH were cut coronally through the needle entry plane (identifiable on the brain surface), and then serially sliced (2$\mathrm{mm}$ thickness) anterior and posterior to the needle entry site. Digital photographs of the serial slices were taken and lesion volume was computed using an image analysis program (Image J, NIH). The total lesion volume $\left(\mathrm{mm}^{3}\right)$ was computed by multiplying the blood clot area (for day 1) and lesion area (for day 3) in each section by the distance between sections [37].

\section{Assessment of BBB disruption with Evans blue extravasation}

A total of 16 rats were randomly selected for assessment of the vascular permeability of the BBB with a modified Evans blue extravasation method [38]. Briefly, 70 hours post- $\mathrm{ICH}$, rats were anesthetized with chloral hydrate $(0.4 \mathrm{~g} / \mathrm{kg})$ and infused via the right femoral vein with $37^{\circ} \mathrm{C}$ Evans blue dye ( $2 \%$ in $0.9 \%$ normal saline, $4 \mathrm{ml} /$ $\mathrm{kg}$ ) over 5 minutes. Two hours later, the rats were perfused with $300 \mathrm{ml}$ normal saline to wash out any remaining dye in the blood vessels and then the brains were removed and sectioned to $2 \mathrm{~mm}$ thickness with a rodent brain matrix. Coronal brain sections were taken starting at $+2 \mathrm{~mm}$ and ending at $-2 \mathrm{~mm}$ from bregma. $\mathrm{BBB}$ permeability was evaluated in the striatum, cortex and cerebellum. The cerebellum was used as anternal control. Each portion was weighed immediately and placed in $1 \mathrm{ml}$ of $0.9 \%$ normal saline for homogenization of the sample. For protein precipitation, $1 \mathrm{ml}$ of $60 \%$ trichloroacetic acid solution was added and vortexed for 2 minutes. The mixture was subsequently cooled for 30 minutes and centrifuged $\left(1500 \mathrm{~g}\right.$ at $\left.4^{\circ} \mathrm{C}\right)$ for another 30 minutes. The absorbance of Evans blue in the supernatant was then measured with a spectrophotometer (Molecular Devices OptiMax, USA) at $610 \mathrm{~nm}$. The dye concentration was expressed as $\mu \mathrm{g} / \mathrm{g}$ of tissue weight and calculated from a standard curve obtained from known amounts of the dye.

\section{Assessment of cytokines}

A total of 16 rats were used for the cytokine assay by ELISA. The ipsilateral striatal tissues were collected before $\mathrm{ICH}$ and on days 1,3 and 7 days post-ICH. After homogenization in lysis buffer (PRO-PREPTM, iNtRON Biotechnology, Korea) and centrifugation at 12,000 $\mathrm{g}$ for 30 minutes, the supernatants were collected and stored frozen at $-80^{\circ} \mathrm{C}$. During quantification, the cytokines (TNF $\alpha$, IL-1 $\beta$ and IL-6) were normalized to $100 \mu \mathrm{g}$ of protein in the supernatant using a commercial ELISA kit from R \& D Systems (Minneapolis, MN, USA) according to the manufacturer's instructions.

\section{Immunohistochemistry}

A total of 8 rats were used for immunohistochemistry on day 3 post-ICH. Rats were anesthetized as described above and transcardially perfused with cold $0.1 \mathrm{M}$ phosphate buffer saline followed by cold $4 \%$ paraformaldehyde in $0.1 \mathrm{M}$ phosphate-buffered saline. Brains were removed and immersed in $4 \%$ paraformaldehyde for 24 hours and 30\% sucrose for another 24 hours. Coronal brain slices $(20 \mu \mathrm{m}$ thickness) were cut. The slices were collected at $+1.0,0.0$, and $-1.0 \mathrm{~mm}$ (center of the hemorrhagic lesion) anterior and posterior to bregma using a cryostat (Leica CM 1900). Three serial slices were taken at each plane (total 9 slices), and processed for the staining and counting of marker-specific cells [37]. Antibodies against OX-42 (1:100; Catalog No. MCA275EL, Serotec, USA) and ED-1 (1:100; Catalog No. MCA241R, Serotec, USA) were used as microglial markers, and NeuN (1:200; Catalog No. MAB377, Chemicon, USA) was used as neuron marker. Tissues sections were incubated with the primary antibodies overnight at $4{ }^{\circ} \mathrm{C}$. The bound primary antibody was visualized by incubation with an appropriate biotinylated secondary antibody followed by the Vectastain $\mathrm{ABC}$ reagents and color development with 3,3'-diaminobenzidine.

Negative control slices from each animal were prepared for immunohistochemical staining processed in an identical manner except the primary antibodies were omitted. OX $-42^{+}$cells with dense immunoreactivity and showing a rod-like appearance were counted as activated microglia. Numbers of positive cells were counted in six squares $\left(1 \mathrm{~mm}^{2}\right)$ randomly located around the lesion in each slice. An average cell number in each plane (total 6 $\mathrm{mm}^{2}$ ) was calculated from 54 squares in 9 planes. All cell counting was done by an independent investigator.

\section{Statistical analysis}

Data were statistically analyzed using Prism software for Student's $t$-test and are presented as mean \pm standard deviation (SD). The statistical comparisons among multiple groups were made using one-way ANOVA, and multiple time points by two way ANOVA followed by Bonferroni correction. In all instances, $\mathrm{n}$ refers to the number of animals in a particular group. A p value of $<$ 0.05 is considered statistically significant.

\section{Results}

UCN reduces neurological deficits

$\mathrm{L} / \mathrm{H}-\mathrm{UCN}$ improved neurological deficits in a dose- and time-dependent manner in collagenase-induced $\mathrm{ICH}$ 
injury (Figure $1 \mathrm{~A})$. In all rats $(\mathrm{n}=24)$, the mNSS was 0 before the $\mathrm{ICH}$, indicating normal neurological function. In the $\mathrm{ICH}+$ saline (control) group $(n=8)$, the mNSS peaked at $9.4 \pm 1.2$ on day 1 and decreased to $7.7 \pm 1.2$ and $5.0 \pm 1.7$ on days 3 and 7 , respectively. In the $\mathrm{ICH}$ $+\mathrm{L}-\mathrm{UCN}(2.5 \mu \mathrm{g} / \mathrm{kg})$ group $(\mathrm{n}=8)$, the mNSS was reduced from $3.9 \pm 2.6$ on day 1 to $1.7 \pm 2.1$ and $1.6 \pm$ 1.3 on days 3 and 7 , respectively. In the $\mathrm{ICH}+\mathrm{H}-\mathrm{UCN}$ $(25 \mu \mathrm{g} / \mathrm{kg})$ group $(\mathrm{n}=8)$, the mNSS was reduced from $6.6 \pm 1.2$ on day 1 to $4.7 \pm 1.3$ and $2.0 \pm 0.8$ on days 3 and 7 , respectively. In addition, both $\mathrm{L}-\mathrm{UCN}$ and $\mathrm{H}-$ UCN significantly reduced neurological deficits on days 1,3 , and 7 ( $\mathrm{p}<0.001$ vs. $\mathrm{ICH}+$ saline group). However, the L-UCN $(2.5 \mu \mathrm{g} / \mathrm{kg})$ group showed a greater reduction in the neurological deficits than the H-UCN (25 $\mu \mathrm{g} / \mathrm{kg}$ ) group on days 1 and 3 ( $\mathrm{p}<0.001$ vs. $\mathrm{ICH}+\mathrm{H}-$ UCN group).

In the autologous blood infusion model of $\mathrm{ICH}(\mathrm{n}=$ $12)$, we selected the dosage of UCN shown to be most effective in the collagenase model $(2.5 \mu \mathrm{g} / \mathrm{kg}$, i.p., $\mathrm{n}=6)$ to investigate the drug's therapeutic effect (Figure 1B). The mNSS of the $\mathrm{ICH}+$ saline (control) group $(\mathrm{n}=6)$ peaked at $8.0 \pm 1.5$ on day 1 and decreased to $6.5 \pm 1.7$ and $3.6 \pm 1.1$ on days 3 and 7 , respectively. Similar to the findings with the collagenase model, treatment with $\mathrm{UCN}(2.5 \mu \mathrm{g} / \mathrm{kg}, \mathrm{n}=6)$ post-ICH significantly reduced the $\mathrm{mNSS}$ in a time-dependent manner to $4.7 \pm 1.0,3.3$ \pm 1.5 , and $1.0 \pm 1.1$ on days 1,3 and 7 ( $p<0.001$ vs. $\mathrm{ICH}+$ saline group), respectively. No animals died in any group during the experiments.

\section{UCN reduces brain edema}

On day 1 post-ICH, $\mathrm{UCN}(\mathrm{ICH}+\mathrm{L}-\mathrm{UCN}$ group) significantly reduced the water content of the ipsilateral hemisphere to $80.7 \pm 0.3 \%$ compared to the $\mathrm{ICH}+$ saline group $(81.4 \pm 0.9 \%)$ (Figure $2 \mathrm{~A}, \mathrm{p}<0.05)$. On day 3 post$\mathrm{ICH}$, water content of the contralateral hemisphere in the sham + saline group was $79.5 \pm 0.8 \%$, while that in the $\mathrm{ICH}+$ saline group was increased to $80.5 \pm 0.6 \%$ (p < $0.05)$; whereas those in the $\mathrm{ICH}+\mathrm{L}-\mathrm{UCN}$ and $\mathrm{ICH}+\mathrm{H}-$ $\mathrm{UCN}$ were insignificantly reduced to $80.0 \pm 0.5 \%$ and $79.4 \pm 0.3 \%$, respectively. The water content of the ipsilateral hemisphere in the sham + saline group was $79.4 \pm$ $0.7 \%$, while that in the $\mathrm{ICH}+$ saline group was markedly increased to $81.9 \pm 0.5 \%(\mathrm{p}<0.001)$ (Figure $2 \mathrm{~B})$. The water content of the ipsilateral hemispheres in both $\mathrm{ICH}$ $+\mathrm{L}-\mathrm{UCN}$ group and $\mathrm{ICH}+\mathrm{H}-\mathrm{UCN}$ group were significantly reduced to $80.6 \pm 0.4 \%(\mathrm{p}<0.001)$ and $79.9 \pm 1.3 \%$ $(\mathrm{p}<0.05)$; but the reduction in brain edema by $\mathrm{H}-\mathrm{UCN}$ was not significantly different from that by L-UCN. No significant differences in water content were seen in the cerebellum between the groups (Figure 2B). These findings indicate that UCN treatment post-ICH significantly reduces the cerebral edema on day 1 and day 3 .

\section{UCN has a hypotensive effect without changing other physiological parameters}

There were no significant differences in baseline readings of mean arterial blood pressure (MABP), heart rate $(\mathrm{HR})$, rectal temperature, $\mathrm{pO}_{2}, \mathrm{pCO}_{2}$ and $\mathrm{pH}$ among the sham + saline, ICH + saline and ICH + L-UCN (2.5 $\mu \mathrm{g} /$ kg, i.p.) groups (Figure 3A \& Table 1).

One hour after ICH, injections of L-UCN $(2.5 \mu \mathrm{g} / \mathrm{kg}$, i. p.) and H-UCN caused a significant decrease in MABP to a maximum of $25 \mathrm{~mm} \mathrm{Hg}$ at 3.0 hours and $40 \mathrm{~mm}$ $\mathrm{Hg}$ at 0.5 hour post treatment (Figure $3 \mathrm{~A}$ ), respectively. The maximum decreases in MABP were accompanied by maximum increases in HR by 35 beats/min (L-UCN) and 45 beats/min (H-UCN) (Table 1$)$. The rectal temperature, $\mathrm{pO}_{2}, \mathrm{pCO}_{2}$ and $\mathrm{pH}$ for the time points studied $(0.5,1$, and 3 hours) were not significantly different between the groups (Table 1).

Because the low dose of UCN $(2.5 \mu \mathrm{g} / \mathrm{kg})$ showed better improvement in the neurological deficits in terms of reducing mNSS than the high dose $(25 \mu \mathrm{g} / \mathrm{kg})$, the dose of $2.5 \mu \mathrm{g} / \mathrm{kg}$ UCN was adopted for subsequent experiments.

\section{A high dose of UCN reduces the perihematomal regional cerebral blood flow (rCBF)}

To clarify whether UCN affected the regional cerebral blood flow, we demonstrated that $\mathrm{ICH}$ alone and $\mathrm{ICH}+$ L-UCN did not affect perihematomal rCBF within 3 hours observation, while $\mathrm{H}-\mathrm{UCN}$ significantly reduced rCBF by approximately $20 \%$ ( $<<0.05$, Figure $3 B$ ).

\section{Penetration of fluorescently labeled UCN through the barrier between blood and striatum}

To examine whether UCN can be transported into the striatal parenchyma to exert its function, we administered Alexa Fluor ${ }^{\circledR}$ 488-labeled-UCN i.p. one hour post$\mathrm{ICH}$. The results showed that, three hours after i.p. injection of fluorescently labeled UCN $(2.5 \mu \mathrm{g} / \mathrm{kg})$, the labeled UCN was localized in the striatum on both ipsilateral (Figure $4 \mathrm{~A}$ to $4 \mathrm{~F}$ ) and contralateral sides (Figure $4 \mathrm{G}$ to $4 \mathrm{~L}$ ). The transport of intact $\mathrm{UCN}$ into the brain was confirmed by dual labeling with an anti-UCN antibody, which overlaps with the Alexa Fluor ${ }^{\circledR} 488$ labeledUCN (Figure $4 \mathrm{M}$ to $4 \mathrm{P}$ ). The presence of UCN appeared to be more prominent on the ipsilateral side. These results indicate that the UCN can be transported from the systemic circulation into the striatum.

\section{UCN reduces lesion volume but not hemorrhagic volume} The hemorrhagic area peaked on day 1 (24 hours) and declined on days 3 and 7 post-ICH (Figure 5A). The hemorrhagic volume on day 1 post- $\mathrm{ICH}$ for the $\mathrm{ICH}+$ saline and $\mathrm{ICH}+\mathrm{L}-\mathrm{UCN}$ groups were $20.4 \pm 3.7$ vs. $20.5 \pm 3.2 \mu \mathrm{l}$, not significantly different between the 


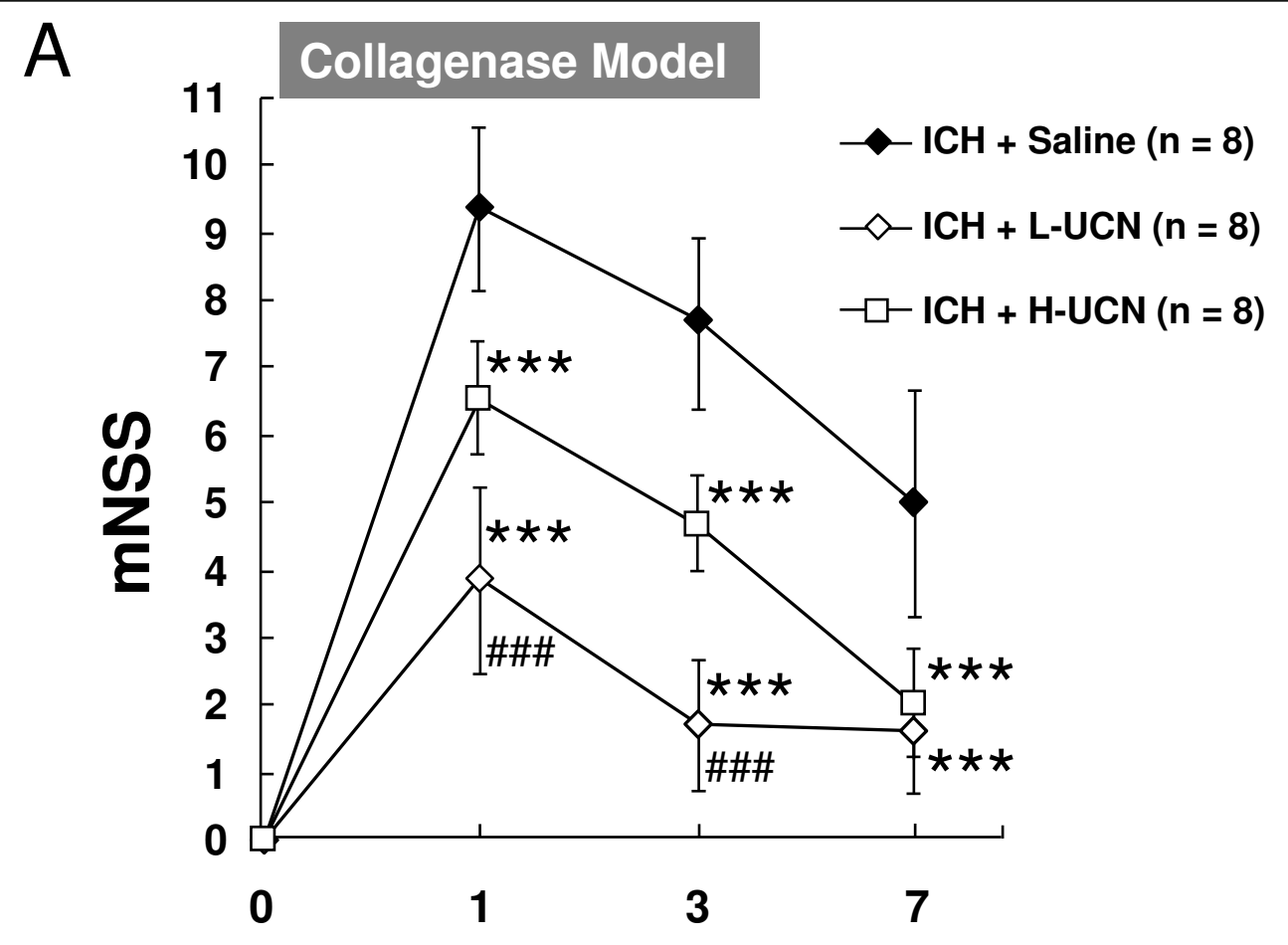

B

\section{Blood Infusion Model}

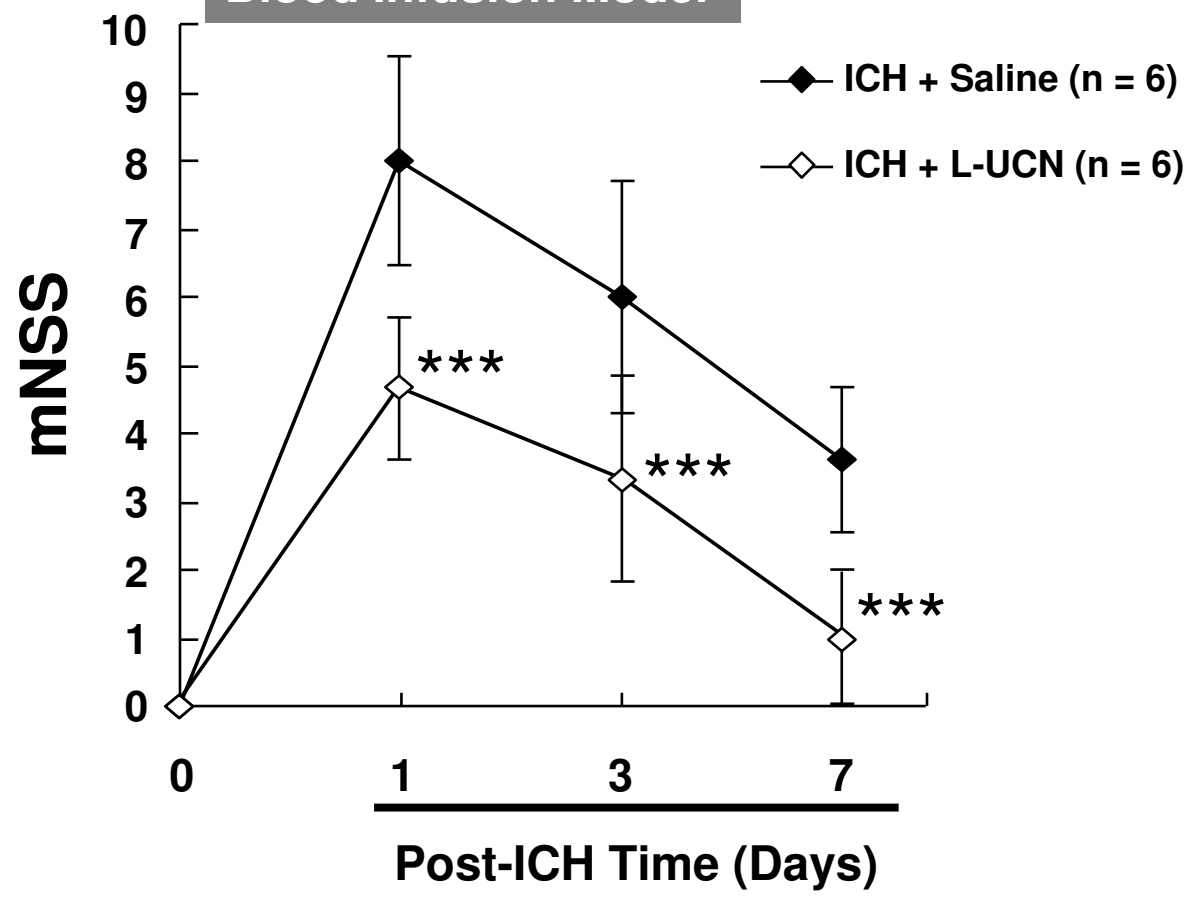

Figure 1 Reduction in ICH-induced neurological deficits by UCN intraperitoneally injected post-injury. UCN was administered i.p. at doses of $2.5 \mu \mathrm{g} / \mathrm{kg}(\mathrm{L})$ or $25 \mu \mathrm{g} / \mathrm{kg}(\mathrm{H}) 60$ minutes after ICH induced by intrastriatal injection of bacterial collagenase VII-S (A) or autologous blood infusion. (B). Modified neurological severity scores (mNSS) were examined on days $0,1,3$, and 7 post-ICH. Values are shown as mean \pm SD. ${ }^{* *} p<0.001$ in ICH + L-UCN or ICH + H-UCN groups vs. ICH + saline group; ${ }^{\# \# \# ~} p<0.001$ in ICH + L-UCN vs. ICH + H-UCN group. Data were analyzed as repeated measures by two-way ANOVA followed by Bonferroni correction. 


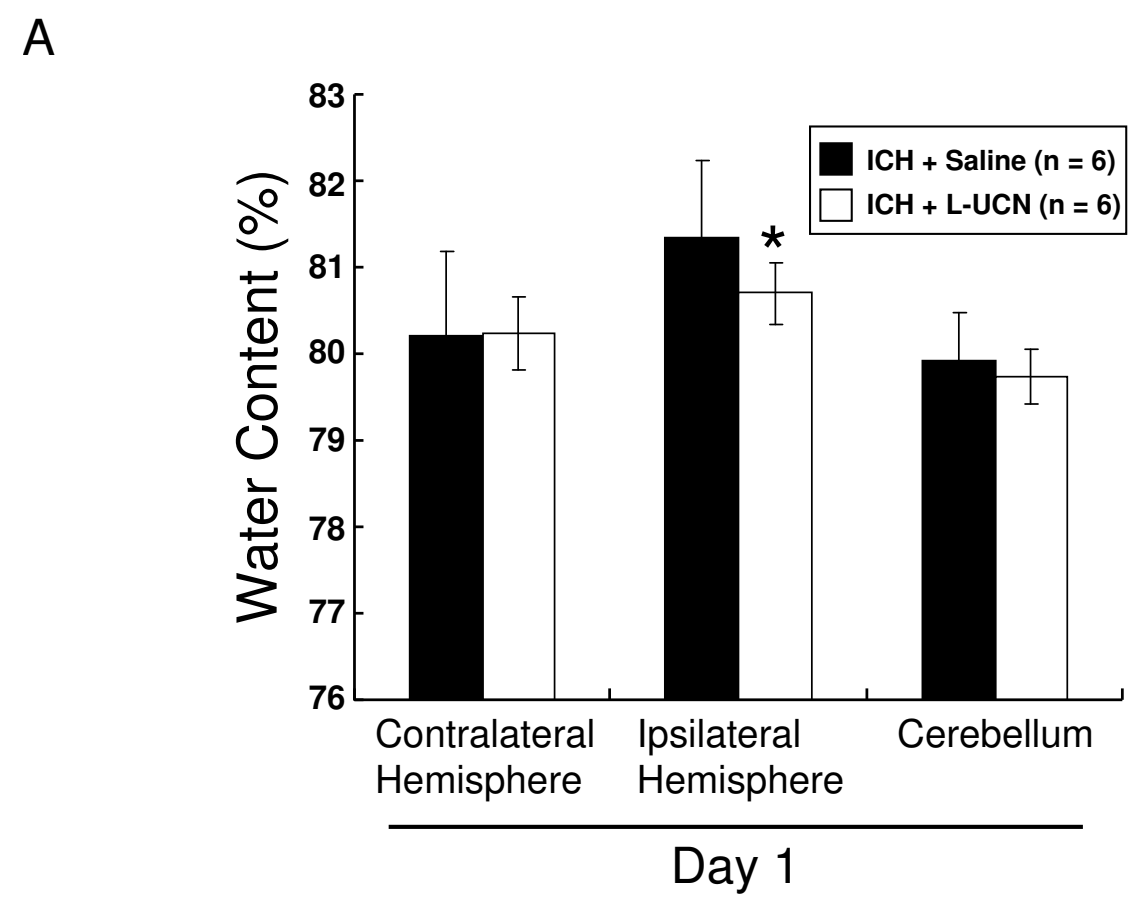

B

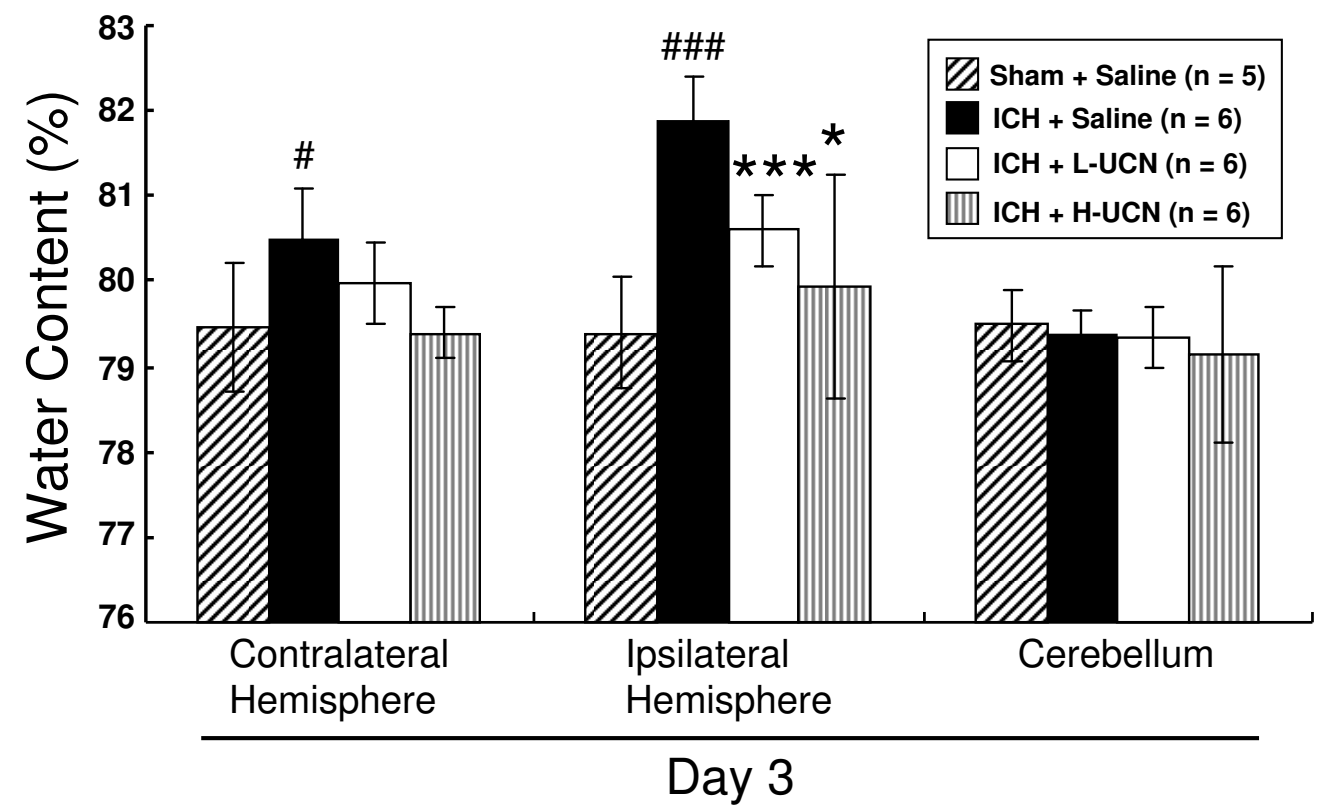

Figure 2 Reduction of brain water content by post-ICH treatment with UCN. Brain water content evaluated on day 1 (A) and 3 (B) post-ICH was expressed as percentage of the wet weight: [(wet weight)-(dry weight)] (wet weight) ${ }^{-1} \times 100 \%$. Values are shown as mean \pm SD, calculated and analyzed by Student's $t$ test. ${ }^{*} p<0.05,{ }^{* * *} p<0.001$ vs. ICH + saline group, ${ }^{\#} p<0.05$, ${ }^{\# \#} p<0.001$ vs. sham + saline group.

groups (Figure 5B), indicating UCN did not affect bleeding (hemorrhagic volume). The hemorrhagic volumes for these two groups $(\mathrm{ICH}+$ saline vs. ICH $+\mathrm{L}-\mathrm{UCN}$ group) on day 3 post-ICH were $1.3 \pm 0.1$ vs. $1.3 \pm 0.0$ $\mu \mathrm{l}$; however, the levels were close to background, indicating complete breakdown of the hemoglobin. Therefore, lesion volume by morphometric measurement (image analysis) was used instead for days 1 and 3 post-ICH. The lesion volume was significantly reduced in $\mathrm{ICH}+\mathrm{L}-\mathrm{UCN}$ compared to the $\mathrm{ICH}+$ saline group 


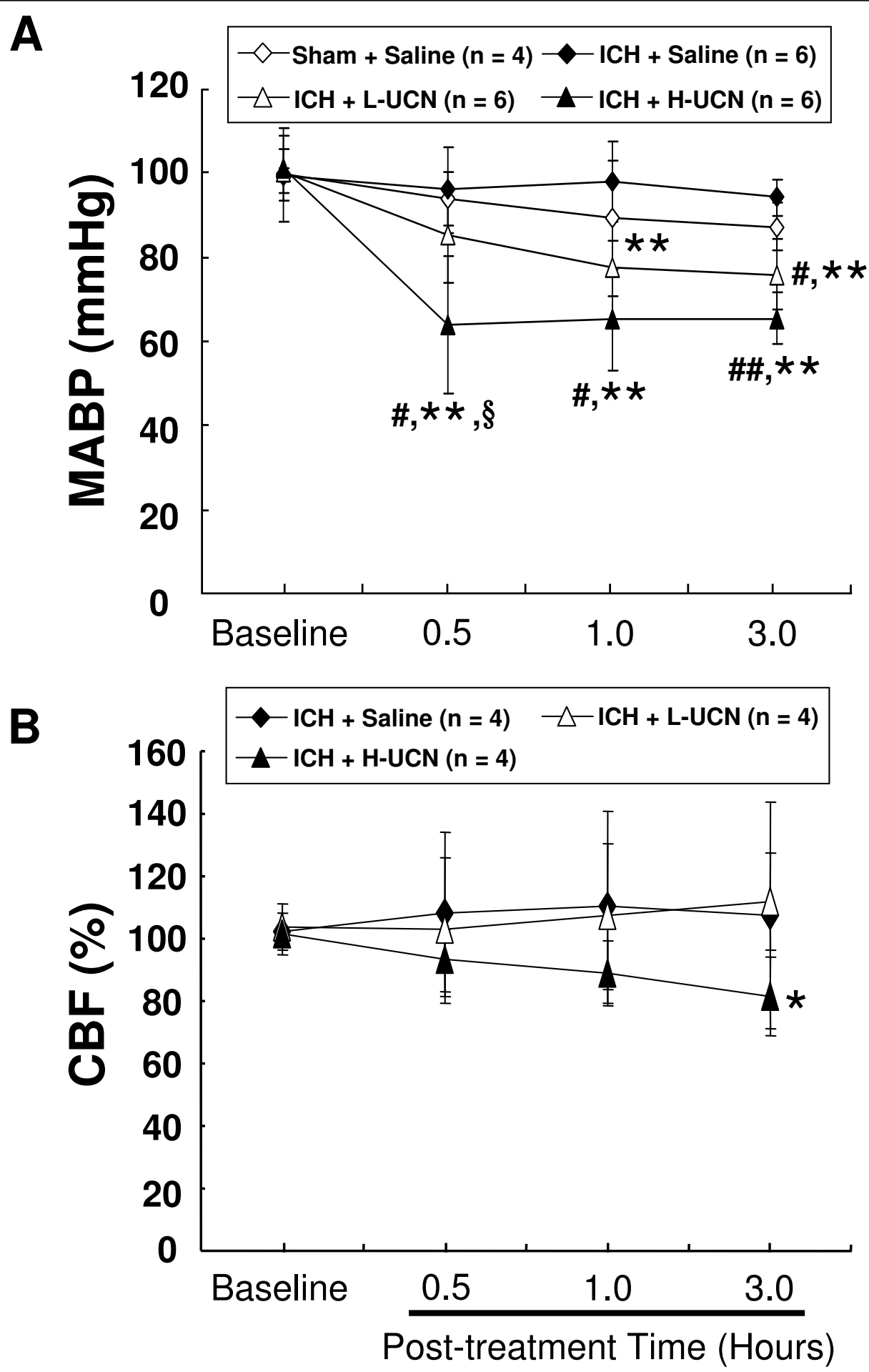

Figure 3 Effects on cardiovascular function and regional cerebral blood flow induced by UCN. (A) Mean arterial blood pressure (MABP) and (B) regional cerebral blood flow (rCBF) were measured up to 3 hours after treatment with low (L)- or high (H)-dose UCN in 4 groups of rats. Values are shown as mean \pm SD. ${ }^{*} p<0.05,{ }^{* *} p<0.01$ in $\mathrm{ICH}+\mathrm{L}-\mathrm{UCN}$ or $\mathrm{ICH}+\mathrm{H}-\mathrm{UCN}$ groups vs. ICH + Saline group; ${ }^{\#} \mathrm{p}<0.05,{ }^{\# \#} \mathrm{p}<0.001$ in $\mathrm{ICH}+\mathrm{L}-\mathrm{UCN}$ or ICH + H-UCN group vs. sham + saline group; ${ }^{\S} \mathrm{p}<0.05 \mathrm{in} \mathrm{ICH}+\mathrm{H}-\mathrm{UCN}$ vs. ICH + L-UCN group. Data were analyzed as repeated measures by two-way ANOVA followed by Bonferroni correction. 
Table 1 Comparison of physiological parameters in sham + saline, ICH + saline, and ICH + L-UCN (2.5 $\mu \mathrm{g} / \mathrm{kg}$, i.p.) groups.

\begin{tabular}{|c|c|c|c|c|c|}
\hline \multirow[b]{2}{*}{ Parameters } & \multirow[b]{2}{*}{ Grouping } & \multirow[b]{2}{*}{ Baseline } & \multicolumn{3}{|c|}{ Post-treatment Time (hours) } \\
\hline & & & 0.5 & 1.0 & 3.0 \\
\hline \multirow[t]{3}{*}{ HR (beats/min) } & Sham + Saline $(n=4)$ & $355.7 \pm 7.0$ & $378.1 \pm 7.9$ & $361.0 \pm 29.4$ & $371.3 \pm 15.0$ \\
\hline & $\mathrm{ICH}+$ Saline $(n=6)$ & $349.5 \pm 48.3$ & $349.5 \pm 41.7$ & $348.8 \pm 51.4$ & $335.0 \pm 15.9$ \\
\hline & $\mathrm{ICH}+\mathrm{L}-\mathrm{UCN}(\mathrm{n}=6)$ & $355.9 \pm 38.3$ & $356.6 \pm 35.1$ & $376.8 \pm 31.9^{*}$ & $389.2 \pm 53.7^{*}$ \\
\hline \multirow[t]{3}{*}{$\mathrm{RT}\left({ }^{\circ} \mathrm{C}\right)$} & Sham + Saline $(n=4)$ & $37.2 \pm 0.2$ & $37.1 \pm 0.3$ & $37.1 \pm 0.2$ & $37.0 \pm 0.2$ \\
\hline & $\mathrm{ICH}+$ Saline $(n=6)$ & $36.9 \pm 0.2$ & $36.9 \pm 0.2$ & $36.9 \pm 0.1$ & $35.6 \pm 2.4$ \\
\hline & $\mathrm{ICH}+\mathrm{L}-\mathrm{UCN}(\mathrm{n}=6)$ & $36.9 \pm 0.1$ & $37.0 \pm 0.1$ & $37.0 \pm 0.2$ & $37.0 \pm 0.1$ \\
\hline \multirow[t]{3}{*}{$\mathrm{pO}_{2}(\mathrm{mmHg})$} & Sham + Saline $(n=4)$ & $92.5 \pm 2.5$ & $93.6 \pm 7.6$ & $95.2 \pm 12.6$ & $102.7 \pm 9.5$ \\
\hline & $\mathrm{ICH}+$ Saline $(\mathrm{n}=6)$ & $95.7 \pm 10.2$ & $104.0 \pm 14.5$ & $104.8 \pm 11.7$ & $126.3 \pm 29.7$ \\
\hline & $\mathrm{ICH}+\mathrm{L}-\mathrm{UCN}(\mathrm{n}=6)$ & $100.0 \pm 8.8$ & $105.2 \pm 12.0$ & $107.3 \pm 10.7$ & $107.9 \pm 11.2$ \\
\hline \multirow[t]{3}{*}{$\mathrm{pCO}_{2}(\mathrm{mmHg})$} & Sham + Saline $(n=4)$ & $50.8 \pm 2.9$ & $50.1 \pm 3.4$ & $45.3 \pm 1.1$ & $44.4 \pm 3.7$ \\
\hline & $\mathrm{ICH}+$ Saline $(\mathrm{n}=6)$ & $49.7 \pm 3.8$ & $45.0 \pm 3.5$ & $46.2 \pm 4.6$ & $36.2 \pm 12.6$ \\
\hline & $\mathrm{ICH}+\mathrm{L}-\mathrm{UCN}(\mathrm{n}=6)$ & $46.7 \pm 3.6$ & $45.1 \pm 2.1$ & $42.6 \pm 4.9$ & $43.3 \pm 3.2$ \\
\hline \multirow[t]{3}{*}{$\mathrm{pH}$} & Sham + Saline $(n=4)$ & $7.39 \pm 0.02$ & $7.40 \pm 0.03$ & $7.41 \pm 0.01$ & $7.42 \pm 0.03$ \\
\hline & $\mathrm{ICH}+$ Saline $(n=6)$ & $7.39 \pm 0.03$ & $7.40 \pm 0.02$ & $7.40 \pm 0.01$ & $7.39 \pm 0.04$ \\
\hline & $\mathrm{ICH}+\mathrm{L}-\mathrm{UCN}(\mathrm{n}=6)$ & $7.37 \pm 0.04$ & $7.39 \pm 0.02$ & $7.42 \pm 0.02$ & $7.42 \pm 0.02$ \\
\hline
\end{tabular}

Values are shown as mean $\pm S D$, calculated and analyzed by Student's $t$ test. ${ }^{*} p<0.05$ vs. ICH + saline group. ICH, intracerebral hemorrhage; HR, heart rate; LUCN, low dose urocortin; i.p., intraperitoneally; RT, rectal temperature.

on day $1\left(54.7 \pm 14.1 \mathrm{~mm}^{3}\right.$ vs. $70.1 \pm 7.0 \mathrm{~mm}^{3}, \mathrm{p}<$ $0.001)$ and day $3\left(23.7 \pm 8.4 \mathrm{~mm}^{3}\right.$ vs. $50.3 \pm 10.7 \mathrm{~mm}^{3}$, $\mathrm{p}<0.001$ ) (Figure $5 \mathrm{C}$ ), suggesting that $\mathrm{UCN}$ can reduce lesion volume.

\section{UCN attenuates BBB disruption}

Since BBB disruption is very likely a contributory cause to the brain edema that peaks on day 3 post- $\mathrm{ICH}$, changes in $\mathrm{BBB}$ disruption were determined by Evans blue dye assay on this day. Representative brain coronal sections (Figure 6A) show Evans blue extravasation on day 3 post-ICH was markedly reduced in the $\mathrm{ICH}$ $+\mathrm{L}-\mathrm{UCN}$ group compared to the $\mathrm{ICH}+$ saline group. Dye concentration in the ipsilateral cortex and striatum of the $\mathrm{ICH}+$ saline group was significantly greater than that of the sham + saline group $(0.8 \pm 0.2 \mu \mathrm{g} / \mathrm{g}$ vs. $0.31 \pm 0.1 \mu \mathrm{g} / \mathrm{g}, \mathrm{p}<0.01$ in cortex; and $4.9 \pm 2.4$ $\mu \mathrm{g} / \mathrm{g}$ vs. $0.6 \pm 0.2 \mu \mathrm{g} / \mathrm{g}, \mathrm{p}<0.01$ in striatum), indicating $\mathrm{ICH}$ causes $\mathrm{BBB}$ disruption of the ipsilateral cortex and striatum (Figure 6B). The $\mathrm{ICH}+\mathrm{L}-\mathrm{UCN}$ group exhibited a significantly lower dye concentration than the $\mathrm{ICH}+$ saline group in the ipsilateral cortex $(0.4 \pm$ $0.1 \mu \mathrm{g} / \mathrm{g}$ vs. $0.8 \pm 0.2 \mu \mathrm{g} / \mathrm{g}, \mathrm{p}<0.01)$ and the striatum $(1.7 \pm 0.9 \mu \mathrm{g} / \mathrm{g}$ vs. $4.9 \pm 2.4 \mu \mathrm{g} / \mathrm{g}, \mathrm{p}<0.05)$, indicating that $\mathrm{UCN}$ significantly reduces the $\mathrm{ICH}$-induced $\mathrm{BBB}$ disruption. Evans blue dye concentrations in other tissues, namely cerebellum and contralateral cerebral cortex and striatum, appeared not to change in all three groups (Figure 6B).

\section{UCN reduces pro-inflammatory cytokine levels in striatal} tissue

Pro-inflammatory cytokine (TNF- $\alpha$, IL-1 $\beta$, and IL-6) levels in the ipsilateral striatum in the $\mathrm{ICH}+$ saline group were significantly increased on day 1 post- $\mathrm{ICH}$ as compared with day 0 pre- $\mathrm{ICH}$ in the sham + saline group; levels of TNF- $\alpha$ (Figure 7A) and IL-1 $\beta$ (Figure $7 \mathrm{~B})$ remained high, albeit getting lower, on days 3 and 7. These high levels of cytokines were significantly reduced in the $\mathrm{ICH}+\mathrm{L}-\mathrm{UCN}$ group on days 1,3 , and 7 post- $\mathrm{ICH}$, but did not return to control (normal) levels. The level of IL-6 (Figure 7C) in the ICH + saline group was also increased on day 1 post- $\mathrm{ICH}$ compared to the pre-ICH (day 0) level in the sham + saline group. This increase was also reduced in the $\mathrm{ICH}+\mathrm{L}-\mathrm{UCN}$ group on day 1 post-ICH. The level of IL-6, however, returned to control level without UCN treatment on days 3 and 7 post-ICH.

\section{UCN reduces microglial activation and neuron loss}

When examined on day 3 post-ICH, the $\mathrm{ICH}+\mathrm{L}-\mathrm{UCN}$ group had a significantly lower number of $\mathrm{OX}-42^{+}$ microglial cells $\left(91 \pm 8\right.$ cells $/ 6 \mathrm{~mm}^{2}$ vs. $168 \pm 7$ cells $/ 6$ $\mathrm{mm}^{2}, \mathrm{p}<0.05$, Figure $\left.8 \mathrm{~B}\right)$ and ED- ${ }^{+}$cells $(62 \pm 31$ cells $/ 6 \mathrm{~mm}^{2}$ vs. $140 \pm 21$ cells $/ 6 \mathrm{~mm}^{2}, \mathrm{p}<0.05$, Figure $8 \mathrm{C})$, as well as a significant reduction in $\mathrm{NeuN}^{+}$cell loss $\left(393 \pm 78\right.$ cells $/ 6 \mathrm{~mm}^{2}$ vs. $217 \pm 42$ cells $/ 6 \mathrm{~mm}^{2}, \mathrm{p}<$ 0.05 , Figure $8 \mathrm{D})$ compared to the $\mathrm{ICH}+$ saline group (Figure 8E). 


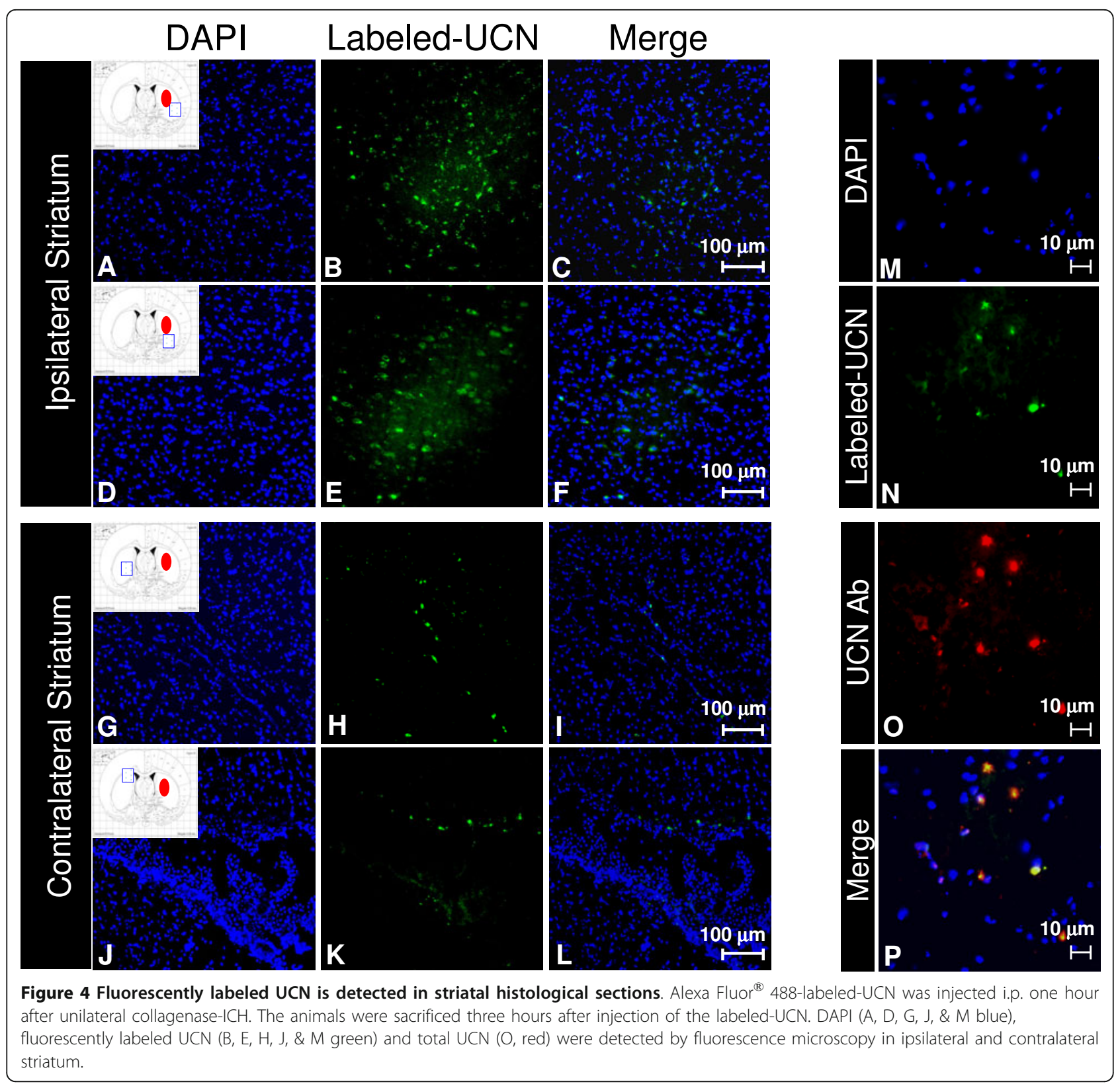

\section{Discussion}

This is the first demonstration of a systemically administered very low dose of UCN offering beneficial effects in many aspects of with brain damage caused by $\mathrm{ICH}$, including overall neurological function. A paradoxical dose-response was noted in which the higher dose (25 $\mu \mathrm{g} / \mathrm{kg})$ of UCN was less effective than the low dose $(2.5$ $\mu \mathrm{g} / \mathrm{kg}$ ) of UCN in attenuating neurological deficits. Brain edema leads to an increase in intracranial pressure (ICP), causing severe tissue damage. Our water content results indicate relief of edema by UCN. However, there were no significant differences between the two doses of $\mathrm{UCN}$ in effectively reducing brain edema, indicating the maximum effect on reduction of brain edema is reached at $2.5 \mu \mathrm{g} / \mathrm{kg}$ of UCN (Figure 2).

An alternative explanation of this discrepancy might be attributed to a potent hypotensive effect of UCN [9,16,25-29]. Consistent with these studies, post-treatment with high-dose UCN in our study caused a profoundly lowered MABP by $40 \mathrm{mmHg}$, which may reduce the cerebral perfusion pressure (CPP) and result in a time-dependent reduction of the striatal regional cerebral blood flow (Figure 3B) at 3 hours. Therefore, the post-treatment with high-dose $\mathrm{UCN}$ results in a relative hypoperfusion, which may limit the effect in reducing the brain edema and neurological deficit. 


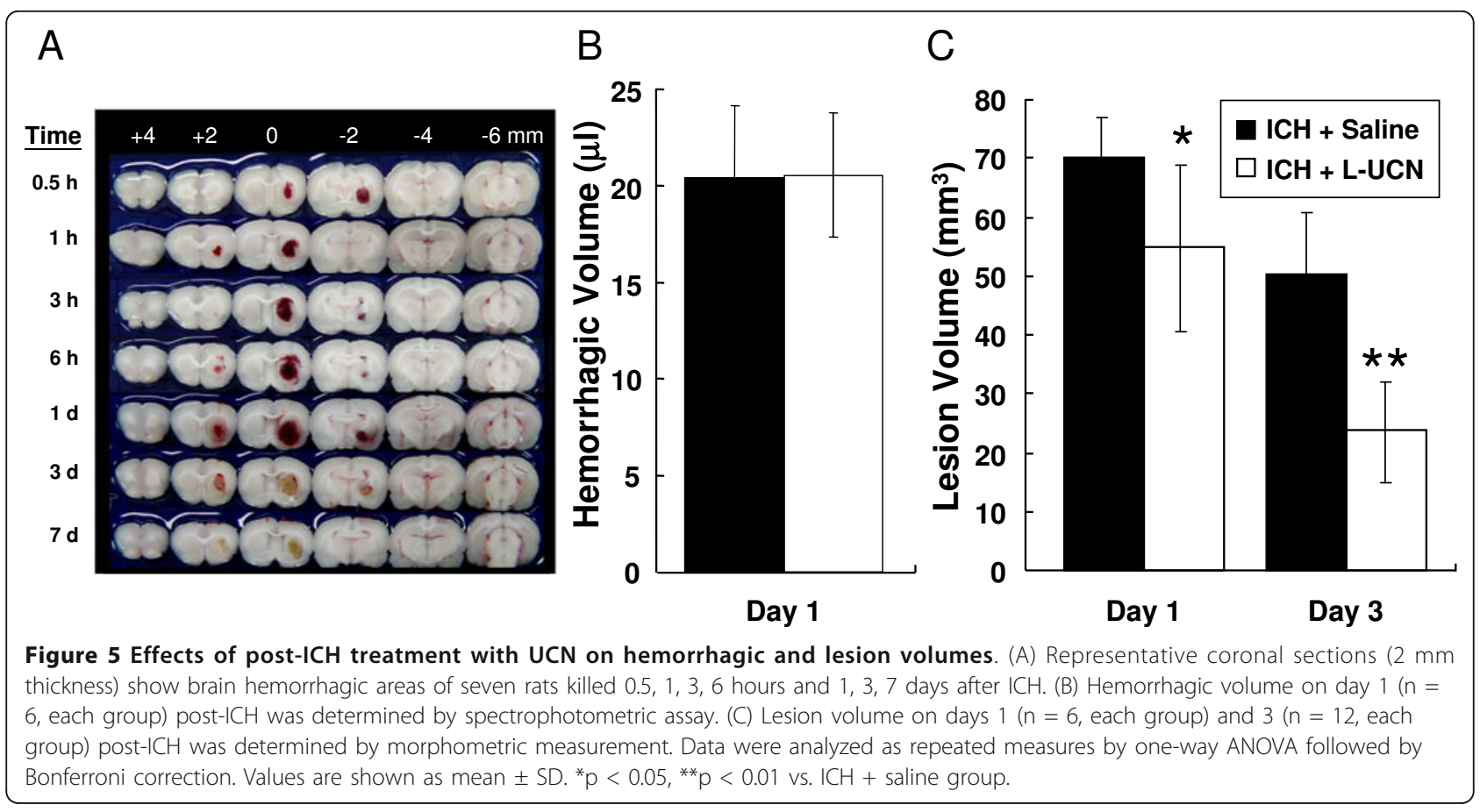

Alternatively, other effects such as UCN induces the anxiogenic effect $[39,40]$ and reduces energy expenditure $[9,41]$ may be also factors contributing to the discrepancy of neurological improvement.

Many reports have shown that $\mathrm{UCN}$ is a potent appetite suppressor $[9,42]$. In our experiments, one bolus injection of UCN (L-UCN $2.5 \mu \mathrm{g} / \mathrm{kg}$, i.p. or $\mathrm{H}$ $\mathrm{UCN} 25 \mu \mathrm{g} / \mathrm{kg}$, i.p) did not reduce the body weight of $\mathrm{ICH}$-injured rats compared to the $\mathrm{ICH}+$ saline group (data not shown). The fact that a low dose is effective without causing significant untoward effects offers the advantage of a wide therapeutic safety margin, and lends support, along with the effectiveness of systemic administration, to the potential of UCN for possible clinical applications.

$\mathrm{UCN}$ is relatively stable in the circulation [42] and the permeability of $\mathrm{UCN}$ across the intact $\mathrm{BBB}$ is lower than other peptides and larger proteins [42]. In our study, an i.p. administration was proved to be effective. To examine whether UCN gets into the neural tissues, we injected fluorescently-labeled UCN and monitored its presence in the striatum. The results indicated appreciable uptake of intact UCN (confirmed by dual labeling with an anti-UCN antibody) in striatal tissues, most prominently in the ipsilateral hemisphere. This can be explained by the fact that several factors including leptin, glucose, insulin, and the proinflammatory cytokine and adipokine TNF- $\alpha$ facilitate the passage of UCN across the intact BBB [42-45]. The identification of the fluorescently labeled UCN in the injured striatum as early as 3 hours after administration may also explain the early effects of UCN in reducing the neurological deficits and inflammatory injuries (as indicated by reduced proinflammatory cytokine expression) on day 1 post-ICH.

Furthermore, we also found that intact UCN can be transported into the contralateral and ipsilateral hemispheres even in naïve brain (without sham surgery) (data not shown). The kinetics of UCN crossing the $\mathrm{BBB}$ into the brain were not appreciably different between the high dose and the low dose of UCN in $\mathrm{ICH}$-induced injury brain. This phenomenon may be due to saturable entry of UCN through the BBB, inhibited by excess UCN $[15,46]$. Detailed mechanisms of UCN passage into the brain remain to be elucidated. It should however be noted that even if UCN can enter the brain, there is no proof that it functionally protects the brain at the level of the CNS. The protective effects could be mediated through peripheral effects, e.g. changes in MABP, cerebral perfusion pressure (CPP), or reduction in immune infiltration.

Glial cells (mainly astrocytes and microglia), apart from providing physical support and insulation, play important roles in maintenance and repair of neurons as well as neural transmission [47]. The cell types involved in injury and repair therefore warrant close examination. UCN was able to suppress both microglial activation and neuronal loss. These findings are compatible with UCN suppressing pro-inflammatory cytokine expression, thereby limiting inflammation and neuronal loss. 


\section{A}
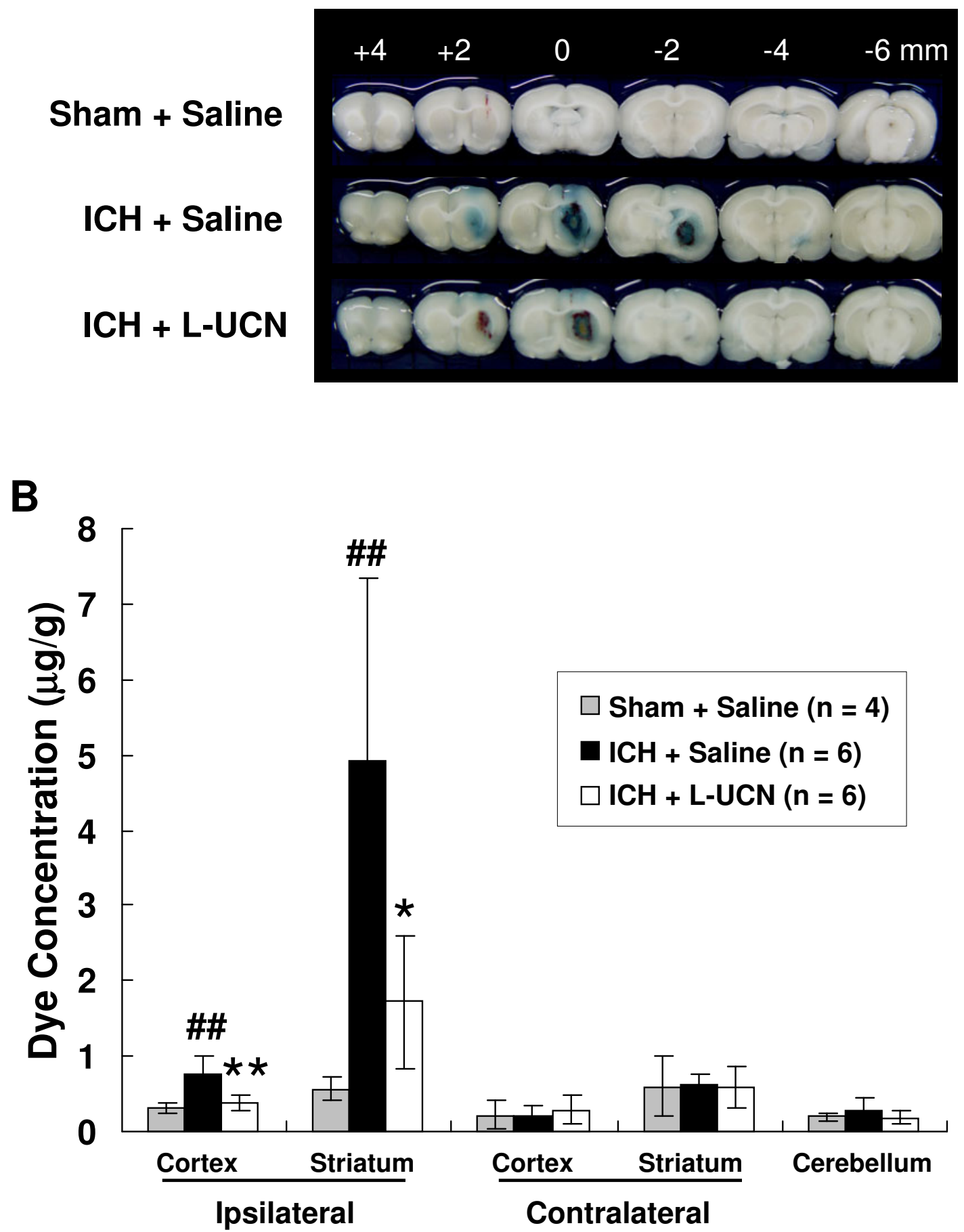

Figure 6 Reduction in BBB disruption in ipsilateral cortex and striatum by post-ICH treatment with UCN. (A) Representative brain coronal sections (2 mm thickness) show Evans blue extravasation on day 3 post- $\mathrm{ICH}$. (B) Comparisons of dye concentrations in various brain tissues among sham + saline, ICH + saline, and ICH + L-UCN (2.5 $\mu \mathrm{g} / \mathrm{kg}$, i.p.) groups. The dye concentration is expressed as $\mu \mathrm{g} / \mathrm{g}$ of tissue weight and calculated from a standard curve obtained from known amounts of the dye. Values are shown as mean \pm SD, calculated and analyzed by Student's $t$ test. ${ }^{*} \mathrm{p}<0.05,{ }^{* *} \mathrm{p}<0.01$, vs. ICH + saline group, ${ }^{\# \#} \mathrm{p}<0.01 \mathrm{vs}$. sham + saline group. 

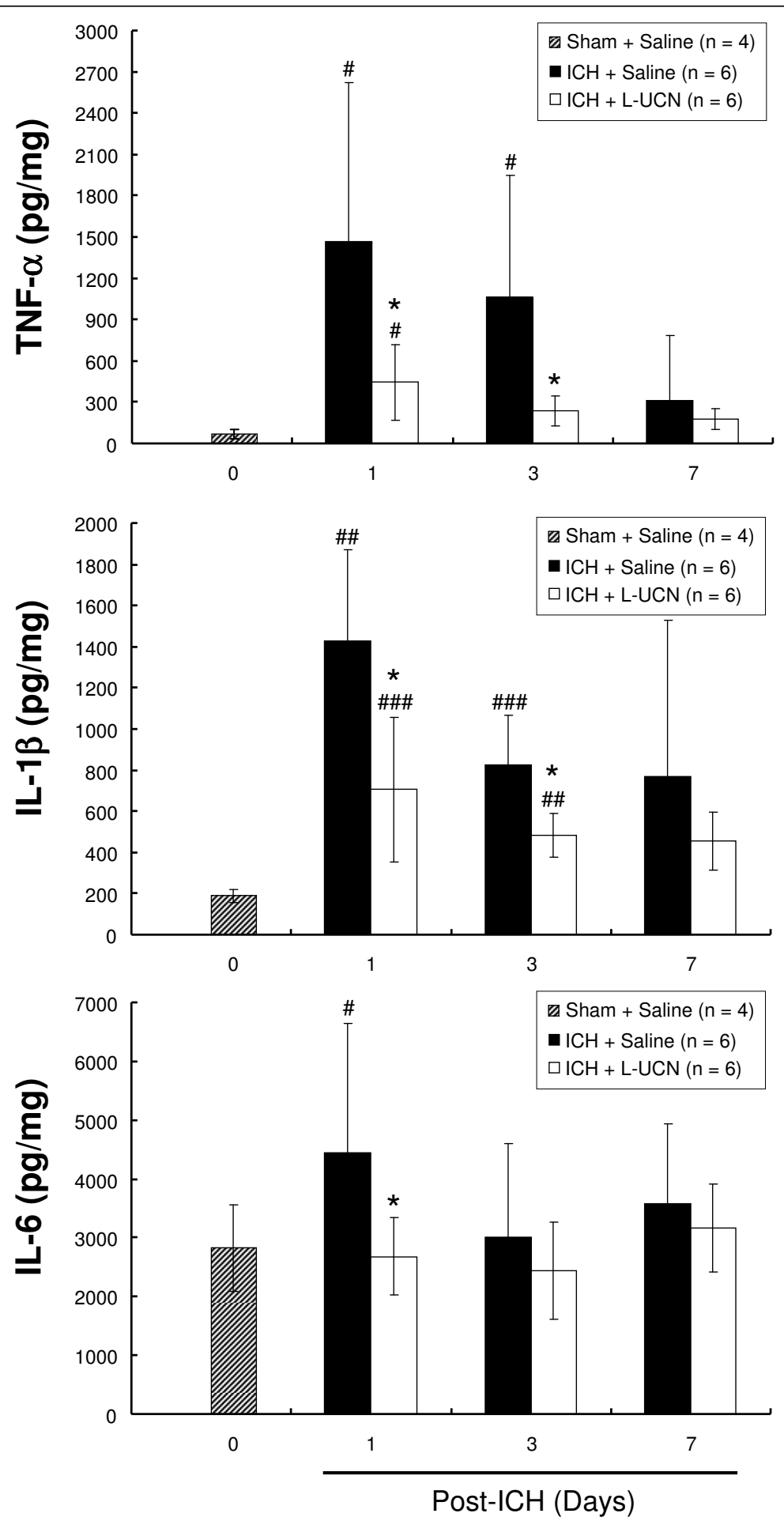

Figure 7 Levels of TNF- $\alpha(A), I L-1 \beta$ (B) and IL-6 (C) in striatal tissues. After ICH, the ipsilateral striatal tissues were collected at the indicated times. The content of cytokines in the tissues was determined as described in Materials and Methods. Values are shown as mean \pm SD. ${ }^{*} p<$ 0.05 vs. ICH + saline group, $\# p<0.05,{ }^{\# \#} p<0.01, \# \# p<0.001$ vs. sham + saline group. Data were analyzed as repeated measures by one way ANOVA followed by Bonferroni correction. 


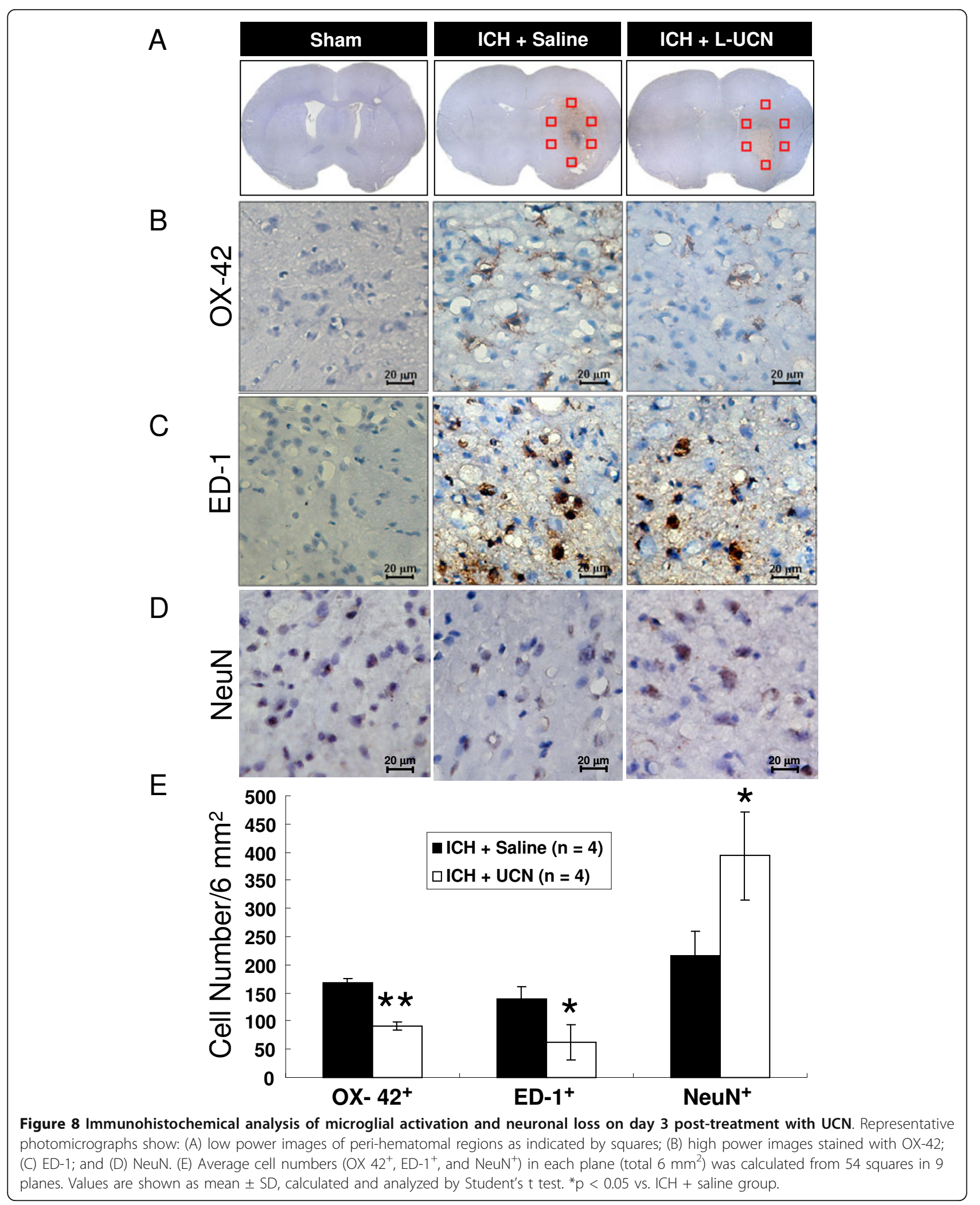


Although the main role for microglial activation after brain injury is to clear cell debris and the hematoma, neuroinflammation due to over-activated microglia that release toxic factors plays a major role in further brain damage in ICH $[17,18,48]$, especially in the early brain injury $[8,48,49]$.

Several drugs can produce anti-oxidative effects, which protect microglia from damage, preserving their phagocytotic function for faster hematoma clearance and promotion of neuroprotection in ICH [50-52]. However, in our experiments, UCN reduced over-activated microglia that release pro-inflammatory cytokines such as TNF- $\alpha$, IL-1 $\beta$ and IL-6, suggesting UCN has an anti-inflammatory effect. However, our results indicate no effect of $\mathrm{UCN}$ on hematoma clearance. This discrepancy may be due to different types of microglial activation and different types of anti-inflammatory mechanisms.

Recently, microglial activation inhibitors such as MIF (microglia/macrophage inhibitory factor, tuftsin fragment 1-3, Thr-Lys-Pro) and minocycline, have shown a promising reduction in brain edema and tissue damage, and attenuation of functional deficits in experimental $\mathrm{ICH}[49,53]$. We infer that UCN is an anti-inflammatory neuropeptide that inhibits activated microglia and reduces neuronal loss in vivo.

Whether UCN can attenuate bleeding (hemorrhagic) volume remains a question. We found that post-ICH treatment with UCN did not affect the accumulated hemorrhagic volume at 24 hours (day 1) after UCN treatment, but significantly reduced the lesion volume on day 1 and 3 after $\mathrm{ICH}$. Besides, our in vitro study also demonstrated that UCN ( $5 \mathrm{nM}-5 \mu \mathrm{M})$ did not inhibit collagenase enzyme activity (data not shown); therefore, UCN may not reduce collagenase-induced bleeding. These results indicate that the neuroprotective effect of UCN may not be due to reducing bleeding volume, but most likely due to reducing brain edema and neuroinflammation.

Clinically, a stroke patient is usually admitted to the emergency clinic within 1-3 hours. The patient should be treated as early as possible, so we chose to administer $\mathrm{UCN}$ at one hour post-ICH. The effectiveness of the low dose of UCN is consistent with our previous in vitro studies, which demonstrated that femtomolar concentrations of UCN can inhibit TNF- $\alpha$ production in cultured microglia treated with endotoxin [22,23]. As compared with other in vivo anti-inflammation studies mentioned above [49,53], the effective dosage of UCN $(0.5 \mathrm{nmol} / \mathrm{kg}$, or $2.5 \mu \mathrm{g} / \mathrm{kg}$, i.p.) in the present study is much more potent than MIF $(\approx 1.67 \mu \mathrm{mol} / \mathrm{kg}$, or $604 \mu \mathrm{g} / \mathrm{kg})$ or minocycline $(\approx 0.1 \mathrm{mmol} / \mathrm{kg}$ or $45 \mathrm{mg} / \mathrm{kg})$. Therefore, UCN is a potential agent for clinically therapeutic purposes.

However, the biological activities of UCN in inflammation remain controversial. Although most studies agree that $\mathrm{UCN}$ is a powerful anti-inflammatory agent
[22-24,54-56], some have found a pro-inflammatory effect, causing vasculitis and increased pulmonary vascular permeability [57-59]. This disparity may be due to the different subtypes of CRF receptors distributed in the CNS and periphery, and different cells and tissues, or to different effects of UCN in local and systemic administration $[9,60]$.

$\mathrm{UCN}$ is a cardioprotective agent in ischemia/reperfusion-induced injuries. Activation of the PI3K/Akt and ERK $1 / 2$ signaling pathways is part of the underlying mechanism in cardiomyocytes [17-20]. Furthermore, Abuirmeileh and colleagues infer that UCN can restore nigrostriatal functions following endotoxin-induced neuroinflammation in vivo [21]. We also demonstrated that the neuroprotective effect of UCN is mediated via inhibition of GSK-3 $\beta$ and HDAC in an in vitro study [22]. This current study extends the beneficial effects of UCN in the $\mathrm{ICH}$ rat model. However, the underlying mechanisms by which UCN reduces ICH-induced injury remain unclear and need further clarification.

\section{Conclusion}

$\mathrm{UCN}$ is a potent anti-inflammatory agent that is a potential target for drug design and development for clinical use. Further investigation of UCN for clinical treatment of ICH is highly warranted.

\section{Acknowledgements}

This work was supported in part by grants NSC96-2320-B-016-014-MY3 and NSC-95-2314-B-320-017-01 from the National Science Council, Taiwan, and grants (TCRD98-15 and TCRD 100-13) from the Buddhist Tzu-Chi General Hospital, Hualien, Taiwan.

\section{Author details}

${ }^{1}$ Graduate Institute of Life Sciences, National Defense Medical Center, Taipei, Taiwan. ${ }^{2}$ Department of Medical Research, Buddhist Tzu Chi General Hospital, Hualien, Taiwan. Institute of Medical Sciences, Tzu Chi University, Hualien, Taiwan. ${ }^{4}$ Department of Emergency Medicine, Buddhist Tzu Chi General Hospital, Hualien, Taiwan. ${ }^{5}$ School of Medicine, Tzu Chi University, Hualien, Taiwan. ${ }^{6}$ Graduate Institute of Medical Sciences, College of Medicine, Taipei Medical University, Taipei, Taiwan.

\section{Authors' contributions}

HKL performed all animal-related procedures, analyzed the data and generated the figures. CYP, MJW, JYW and CWH received funding for the project and provided input during the drafting of the manuscript. TYL assisted in evaluation of the behavioral tests and calculated cell density. HFP assessed the staining, and assisted in data collection. JSK assisted in preparation the manuscript. JYW contributed to the design and preparation of the manuscript. All authors read and approved the manuscript.

\section{Competing interests}

The authors declare that they have no competing interests.

Received: 8 July 2011 Accepted: 19 January 2012

Published: 19 January 2012

\section{References}

1. Qureshi Al, Tuhrim S, Broderick JP, Batjer HH, Hondo H, Hanley DF: Spontaneous intracerebral hemorrhage. N Engl J Med 2001, 344:1450-1460. 
2. Rosamond W, Flegal K, Furie K, Go A, Greenlund K, Haase N, Hailpern SM, Ho M, Howard V, Kissela B, et al: Heart disease and stroke statistics-2008 update: a report from the American Heart Association Statistics Committee and Stroke Statistics Subcommittee. Circulation 2008, 117: e25-146.

3. Hanggi D, Steiger HJ: Spontaneous intracerebral haemorrhage in adults: a literature overview. Acta Neurochir (Wien) 2008, 150:371-379, discussion 379.

4. Pouratian N, Kassell NF, Dumont AS: Update on management of intracerebral hemorrhage. Neurosurg Focus 2003, 15:E2.

5. Hankey GJ, Hon C: Surgery for primary intracerebral hemorrhage: is it safe and effective? A systematic review of case series and randomized trials. Stroke 1997, 28:2126-2132.

6. Mendelow AD, Gregson BA, Fernandes HM, Murray GD, Teasdale GM, Hope DT, Karimi A, Shaw MD, Barer DH: Early surgery versus initial conservative treatment in patients with spontaneous supratentorial intracerebral haematomas in the International Surgical Trial in Intracerebral Haemorrhage (STICH): a randomised trial. Lancet 2005, 365:387-397.

7. Morgenstern LB, Demchuk AM, Kim DH, Frankowski RF, Grotta JC: Rebleeding leads to poor outcome in ultra-early craniotomy for intracerebral hemorrhage. Neurology 2001, 56:1294-1299.

8. Wang J: Preclinical and clinical research on inflammation after intracerebral hemorrhage. Prog Neurobiol 2010, 92:463-477.

9. Fekete EM, Zorrilla EP: Physiology, pharmacology, and therapeutic relevance of urocortins in mammals: ancient CRF paralogs. Front Neuroendocrinol 2007, 28:1-27.

10. Hsu SY, Hsueh AJ: Human stresscopin and stresscopin-related peptide are selective ligands for the type 2 corticotropin-releasing hormone receptor. Nat Med 2001, 7:605-611.

11. Pedersen WA, Wan R, Zhang P, Mattson MP: Urocortin, but not urocortin II, protects cultured hippocampal neurons from oxidative and excitotoxic cell death via corticotropin-releasing hormone receptor type I. J Neurosci 2002, 22:404-412.

12. Perrin $M H$, Vale $W W$ : Corticotropin releasing factor receptors and their ligand family. Ann N Y Acad Sci 1999, 885:312-328.

13. Stevens SL, Shaw TE, Dykhuizen E, Lessov NS, Hill JK, Wurst W, StenzelPoore MP: Reduced cerebral injury in CRH-R1 deficient mice after focal ischemia: a potential link to microglia and atrocytes that express $\mathrm{CRH}$ R1. J Cereb Blood Flow Metab 2003, 23:1151-1159.

14. Van Pett K, Viau V, Bittencourt JC, Chan RK, Li HY, Arias C, Prins GS, Perrin $M$, Vale W, Sawchenko PE: Distribution of mRNAs encoding CRF receptors in brain and pituitary of rat and mouse. J Comp Neurol 2000, 428:191-212.

15. Pan W, Kastin AJ: Urocortin and the brain. Prog Neurobiol 2008, 84:148-156.

16. Torpy DJ, Webster EL, Zachman EK, Aguilera G, Chrousos GP: Urocortin and inflammation: confounding effects of hypotension on measures of inflammation. Neuroimmunomodulation 1999, 6:182-186.

17. Brar BK, Jonassen AK, Stephanou A, Santilli G, Railson J, Knight RA, Yellon DM, Latchman DS: Urocortin protects against ischemic and reperfusion injury via a MAPK-dependent pathway. J Biol Chem 2000, 275:8508-8514.

18. Gordon JM, Dusting GJ, Woodman OL, Ritchie RH: Cardioprotective action of CRF peptide urocortin against simulated ischemia in adult rat cardiomyocytes. Am J Physiol Heart Circ Physiol 2003, 284:H330-336.

19. Lawrence KM, Chanalaris A, Scarabelli T, Hubank M, Pasini E, Townsend PA, Comini L, Ferrari R, Tinker A, Stephanou A, et al: K(ATP) channel gene expression is induced by urocortin and mediates its cardioprotective effect. Circulation 2002, 106:1556-1562.

20. Liu CN, Yang C, Liu XY, Li S: In vivo protective effects of urocortin on ischemia-reperfusion injury in rat heart via free radical mechanisms. Can J Physiol Pharmacol 2005, 83:459-465.

21. Abuirmeileh A, Harkavyi A, Lever R, Biggs CS, Whitton PS: Urocortin, a CRFlike peptide, restores key indicators of damage in the substantia nigra in a neuroinflammatory model of Parkinson's disease. J Neuroinflammation 2007, 4:19.

22. Huang HY, Lin SZ, Chen WF, Li KW, Kuo JS, Wang MJ: Urocortin modulates dopaminergic neuronal survival via inhibition of glycogen synthase kinase-3beta and histone deacetylase. Neurobiol Aging 2011, 32:1662-1677.

23. Wang MJ, Lin SZ, Kuo JS, Huang HY, Tzeng SF, Liao CH, Chen DC, Chen WF: Urocortin modulates inflammatory response and neurotoxicity induced by microglial activation. J Immunol 2007, 179:6204-6214.
24. Liew HK, Hsu CW, Wang MJ, Kuo JS, Li TY, Peng HF, Wang JY, Pang CY: Therapeutic benefit of urocortin in rats with intracerebral hemorrhage. $J$ Neurosurg 2011, DOI: 10.3171/2011.8.JNS101637.

25. Abdelrahman AM, Lin Lim S, Pang CC: Influence of urocortin and corticotropin releasing factor on venous tone in conscious rats. Eur $\mathrm{J}$ Pharmacol 2005, 510:107-111.

26. Abdelrahman AM, Pang CC: Regional haemodynamic effects of urocortin in the anaesthetized rat. Eur J Pharmacol 2003, 466:317-321.

27. Gardiner SM, March JE, Kemp PA, Bennett T: A comparison between the cardiovascular actions of urocortin 1 and urocortin 2 (stresscopin-related peptide) in conscious rats. J Pharmacol Exp Ther 2007, 321:221-226.

28. Parkes DG, May CN: Urocortin: A Novel Player in Cardiac Control. News Physiol Sci 2000, 15:264-268.

29. Parkes DG, Weisinger RS, May CN: Cardiovascular actions of CRH and urocortin: an update. Peptides 2001, 22:821-827.

30. MacLellan CL, Silasi G, Poon CC, Edmundson CL, Buist R, Peeling J, Colbourne F: Intracerebral hemorrhage models in rat: comparing collagenase to blood infusion. J Cereb Blood Flow Metab 2008, 28:516-525.

31. Rosenberg GA, Mun-Bryce S, Wesley M, Kornfeld M: Collagenase-induced intracerebral hemorrhage in rats. Stroke 1990, 21:801-807.

32. Chen J, Li Y, Wang L, Zhang Z, Lu D, Lu M, Chopp M: Therapeutic benefit of intravenous administration of bone marrow stromal cells after cerebral ischemia in rats. Stroke 2001, 32:1005-1011.

33. Xue M, Del Bigio MR: Intracerebral injection of autologous whole blood in rats: time course of inflammation and cell death. Neurosci Lett 2000, 283:230-232.

34. Yang GY, Betz AL, Chenevert TL, Brunberg JA, Hoff JT: Experimental intracerebral hemorrhage: relationship between brain edema, blood flow, and blood-brain barrier permeability in rats. J Neurosurg 1994, 81:93-102.

35. Chu K, Jeong SW, Jung KH, Han SY, Lee ST, Kim M, Roh JK: Celecoxib induces functional recovery after intracerebral hemorrhage with reduction of brain edema and perihematomal cell death. J Cereb Blood Flow Metab 2004, 24:926-933.

36. Park HK, Chu K, Lee ST, Jung KH, Kim EH, Lee KB, Song YM, Jeong SW Kim M, Roh JK: Granulocyte colony-stimulating factor induces sensorimotor recovery in intracerebral hemorrhage. Brain Res 2005, 1041:125-131.

37. Jung KH, Chu K, Jeong SW, Han SY, Lee ST, Kim JY, Kim M, Roh JK: HMGCoA reductase inhibitor, atorvastatin, promotes sensorimotor recovery, suppressing acute inflammatory reaction after experimental intracerebral hemorrhage. Stroke 2004, 35:1744-1749.

38. Esen F, Erdem T, Aktan D, Orhan M, Kaya M, Eraksoy H, Cakar N, Telci L: Effect of magnesium sulfate administration on blood-brain barrier in a rat model of intraperitoneal sepsis: a randomized controlled experimental study. Crit Care 2005, 9:R18-23.

39. Moreau JL, Kilpatrick G, Jenck F: Urocortin, a novel neuropeptide with anxiogenic-like properties. Neuroreport 1997, 8:1697-1701.

40. Spina MG, Merlo-Pich E, Akwa Y, Balducci C, Basso AM, Zorrilla EP, Britton KT, Rivier J, Vale WW, Koob GF: Time-dependent induction of anxiogenic-like effects after central infusion of urocortin or corticotropin-releasing factor in the rat. Psychopharmacology (Berl) 2002, 160:113-121

41. De Fanti BA, Martinez JA: Central urocortin activation of sympatheticregulated energy metabolism in Wistar rats. Brain Res 2002, 930:37-41.

42. Kastin AJ, Akerstrom V, Pan W: Activation of urocortin transport into brain by leptin. Peptides 2000, 21:1811-1817.

43. Kastin AJ, Akerstrom V: Glucose and insulin increase the transport of leptin through the blood-brain barrier in normal mice but not in streptozotocin-diabetic mice. Neuroendocrinology 2001, 73:237-242.

44. Kastin AJ, Akerstrom V: Pretreatment with glucose increases entry of urocortin into mouse brain. Peptides 2001, 22:829-834.

45. Pan W, Akerstrom V, Zhang J, Pejovic V, Kastin AJ: Modulation of feedingrelated peptide/protein signals by the blood-brain barrier. $J$ Neurochem 2004, 90:455-461

46. Peruzzo B, Pastor FE, Blazquez JL, Schobitz K, Pelaez B, Amat P, Rodriguez EM: A second look at the barriers of the medial basal hypothalamus. Exp Brain Res 2000, 132:10-26.

47. Kettenmann H, Hanisch UK, Noda M, Verkhratsky A: Physiology of microglia. Physiol Rev 2011, 91:461-553. 
48. Wang J, Dore S: Inflammation after intracerebral hemorrhage. J Cereb Blood Flow Metab 2007, 27:894-908.

49. Wang J, Tsirka SE: Tuftsin fragment 1-3 is beneficial when delivered after the induction of intracerebral hemorrhage. Stroke 2005, 36:613-618.

50. Aronowski J, Hall CE: New horizons for primary intracerebral hemorrhage treatment: experience from preclinical studies. Neurol Res 2005, 27:268-279.

51. Zhao X, Grotta J, Gonzales N, Aronowski J: Hematoma resolution as a therapeutic target: the role of microglia/macrophages. Stroke 2009, 40: S92-94.

52. Zhao X, Sun G, Zhang J, Strong R, Song W, Gonzales N, Grotta JC, Aronowski J: Hematoma resolution as a target for intracerebral hemorrhage treatment: role for peroxisome proliferator-activated receptor gamma in microglia/macrophages. Ann Neurol 2007, 61:352-362.

53. Wu J, Yang S, Xi G, Fu G, Keep RF, Hua Y: Minocycline reduces intracerebral hemorrhage-induced brain injury. Neurol Res 2009, 31:183-188.

54. Gonzalez-Rey E, Chorny A, Varela N, O'Valle F, Delgado M: Therapeutic effect of urocortin on collagen-induced arthritis by down-regulation of inflammatory and Th1 responses and induction of regulatory $\mathrm{T}$ cells. Arthritis Rheum 2007, 56:531-543.

55. Torricelli M, Voltolini C, Bloise E, Biliotti G, Giovannelli A, De Bonis M, Imperatore A, Petraglia F: Urocortin increases IL-4 and IL-10 secretion and reverses LPS-induced TNF-alpha release from human trophoblast primary cells. Am J Reprod Immunol 2009, 62:224-231.

56. Xu Y, Zhang R, Chen J, Zhang Q, Wang J, Hu J, Guan X, Jin L, Fu H, Gui B, et al: Urocortin promotes the development of vasculitis in a rat model of thromboangiitis obliterans via corticotrophin-releasing factor type 1 receptors. Br J Pharmacol 2009, 157:1368-1379.

57. Cureton EL, Ereso AQ, Victorino GP, Curran B, Poole DP, Liao M, Harken AH, Bhargava A: Local secretion of urocortin 1 promotes microvascular permeability during lipopolysaccharide-induced inflammation. Endocrinology 2009, 150:5428-5437.

58. Kohno M, Kawahito Y, Tsubouchi Y, Hashiramoto A, Yamada R, Inoue KI, Kusaka Y, Kubo T, Elenkov IJ, Chrousos GP, et al: Urocortin expression in synovium of patients with rheumatoid arthritis and osteoarthritis: relation to inflammatory activity. J Clin Endocrinol Metab 2001, 86:4344-4352.

59. Wu Y, Xu Y, Zhou H, Tao J, Li S: Expression of urocortin in rat lung and its effect on pulmonary vascular permeability. J Endocrinol 2006, 189:167-178.

60. Davidson SM, Yellon DM: Urocortin: a few inflammatory remarks. Endocrinology 2009, 150:5205-5207.

doi:10.1186/1742-2094-9-13

Cite this article as: Liew et al:: Systemic administration of urocortin after intracerebral hemorrhage reduces neurological deficits and neuroinflammation in rats. Journal of Neuroinflammation 2012 9:13.

\section{Submit your next manuscript to BioMed Central and take full advantage of:}

- Convenient online submission

- Thorough peer review

- No space constraints or color figure charges

- Immediate publication on acceptance

- Inclusion in PubMed, CAS, Scopus and Google Scholar

- Research which is freely available for redistribution 